Article

\title{
Intestinal Microbiota Ecological Response to Oral Administrations of Hydrogen-Rich Water and Lactulose in Female Piglets Fed a Fusarium Toxin-Contaminated Diet
}

\author{
Weijiang Zheng ${ }^{1}$, $\mathrm{Xu} \mathrm{Ji}{ }^{1}$, Qing Zhang ${ }^{1}$ and Wen Yao ${ }^{1,2, *}$ \\ 1 Laboratory of Gastrointestinal Microbiology, Jiangsu Key Laboratory of Gastrointestinal Nutrition and \\ Animal Health, College of Animal Science and Technology, Nanjing Agricultural University, Nanjing 210095, \\ China; zhengweijiang@njau.edu.cn (W.Z.); jixuchance@gmail.com (X.J.); zhangqingzee@163.com (Q.Z.) \\ 2 Key Lab of Animal Physiology and Biochemistry, Ministry of Agriculture, Nanjing 210095, China \\ * Correspondence: yaowen67jp@njau.edu.cn; Tel.: +86-25-84399830
}

Received: 27 May 2018; Accepted: 13 June 2018; Published: 16 June 2018

\begin{abstract}
The objective of the current experiment was to explore the intestinal microbiota ecological response to oral administrations of hydrogen-rich water (HRW) and lactulose (LAC) in female piglets fed a Fusarium mycotoxin-contaminated diet. A total of 24 individually-housed female piglets (Landrace $\times$ large $\times$ white; initial average body weight, $7.25 \pm 1.02 \mathrm{~kg}$ ) were randomly assigned to receive four treatments (six pigs/treatment): uncontaminated basal diet (negative control, NC), mycotoxin-contaminated diet (MC), MC diet + HRW (MC + HRW), and MC diet + LAC (MC + LAC) for 25 days. Hydrogen levels in the mucosa of different intestine segments were measured at the end of the experiment. Fecal scoring and diarrhea rate were recorded every day during the whole period of the experiment. Short-chain fatty acids (SCFAs) profiles in the digesta of the foregut and hindgut samples were assayed. The populations of selected bacteria and denaturing gradient gel electrophoresis (DGGE) profiles of total bacteria and methanogenic Archaea were also evaluated. Results showed that Fusarium mycotoxins not only reduced the hydrogen levels in the caecum but also shifted the SCFAs production, and populations and communities of microbiota. HRW treatment increased the hydrogen levels of the stomach and duodenum. HRW and LAC groups also had higher colon and caecum hydrogen levels than the MC group. Both HRW and LAC protected against the mycotoxin-contaminated diet-induced higher diarrhea rate and lower SCFA production in the digesta of the colon and caecum. In addition, the DGGE profile results indicated that HRW and LAC might shift the pathways of hydrogen-utilization bacteria, and change the diversity of intestine microbiota. Moreover, HRW and LAC administrations reversed the mycotoxin-contaminated diet-induced changing of the populations of Escherichia coli (E. coli) and Bifidobacterium in ileum digesta and hydrogen-utilizing bacteria in colon digesta.
\end{abstract}

Keywords: intestinal microbiota; hydrogen-rich water; lactulose; Fusarium mycotoxins; piglets

Key Contribution: Our results showed that both hydrogen-rich water and lactulose administrations protected against the imbalance of intestinal microbiota, reduction of SCFAs production and higher diarrhea rate induced by a Fusarium mycotoxin diet, partly through affecting the communities/populations of microbiota and the evaluation of hydrogen gas. 


\section{Introduction}

Fusarium mycotoxins are secondary metabolites of fungi, produced by several kinds of Fusarium species that occur naturally worldwide in cereal grains and animal feed [1]. Among the Fusarium mycotoxins, deoxynivalenol (DON) and zearalenone (ZEN) are of special importance as they are formed under predisposing environmental conditions in the field prior to harvest and cannot be completely avoided by strategies [2]. Consumption of Fusarium mycotoxins is widely considered as a serious health hazard issue for both animals and human beings, due to their potent toxicity on the gastrointestinal (GI) tract, with symptoms including nausea, vomiting, diarrhea, and oxidative damage [3]. The GI tract is the place where mycotoxin absorption and metabolism occur. Therefore, interactions between the mycotoxins and intestinal microbiota play a major role in the toxicology of mycotoxins [4]. It has been shown that intestinal bacteria are able to bind, transform, degrade, and transfer mycotoxins in vivo and in vitro [5]. Increasingly attention has been paid on how mycotoxin exposure impacts the intestinal microbiota. Previous studies have shown that the profiles and biodiversity of intestinal microbiota were rapidly and clearly modified in pig exposure to a mycotoxin-contaminated diet [6,7]. Considering the functional effects of microbiota, many methods have been attempted to balance gut microbiota to normalize microbiota in intestinal tracts and keep the host healthy. For example, supplementation of nutritional elements, probiotics, and prebiotics or symbiotic, etc.

Hydrogen gas is one of the metabolites of bacterial fermentation in the gut, which has been proven to act as a novel antioxidant [8]. It has been demonstrated that $\mathrm{H}_{2}$ could penetrate cytoplasmic membranes, targets intracellular organelles, and selectively neutralizes cytotoxic reactive oxygen species (ROS) [9]. As a result, hydrogen gas has been applied in many disease models, such as dextran sodium sulfate (DSS)-induced colon inflammatory [10] and intestinal ischemia-reperfusion injuries [11]. A recent report described that $70 \%$ of GI microbial species that encoded genetic capacity to metabolize $\mathrm{H}_{2}$ [12], indicating that $\mathrm{H}_{2}$ levels might affect the gut microbial activity, population, or community. Interestingly, one recent study reported that molecular hydrogen-dissolved alkaline electrolyzed water (AEW) had a strong antimicrobial effect and significantly reduced populations of pathogenic bacteria, such as Escherichia coli O157 and Salmonella [13]. Xiao et al. also reported that HRW oral gavage resulted in retention of the total abdominal irradiation (TAI)-shifted intestinal bacterial composition in mice [14]. As we know, $\mathrm{H}_{2}$ is produced continuously under a normal physiological condition in mammalian animals, primarily during the fermentation of non-digestible carbohydrates by bacteria in the large intestine. Therefore, administration of hydrogen-producing prebiotics might also be a viable method to provide functional $\mathrm{H}_{2}$ to animals and humans. Lactulose is a synthetic non-absorbable disaccharide consisting of fructose and galactose [15]. It has been reported that microbial fermentation of lactulose in the hindgut could induce dramatic amounts of endogenous $\mathrm{H}_{2}$, providing beneficial effects on liver regeneration [16] and cerebral ischemia-reperfusion injury [17] in rats. In addition, lactulose administration could also lead to the production of short-chain fatty acids (SCFAs) and methane, increasing the diversity and creating a distinct microbiota community in piglets $[18,19]$.

Although HRW and LAC have shown the modifications of microbiota, the effects of HRW or LAC on mycotoxin-induced microbiota imbalance in piglets have not ever been studied. Here, the rationale underlying this study is that HRW or LAC might maintain the intestinal microbiota communities and bacteria populations, thus affecting SCFAs production and eventually improving the health status of female weaning piglets. Therefore, the impacts of HRW and LAC on fecal scoring, diarrhea rate, SCFAs production, intestinal microbiota communities, and populations in piglets fed a Fusarium mycotoxin-contaminated diet were explored in this study.

\section{Results}

\subsection{Hydrogen Levels in Intestinal Segments}

At the end of the experiment, that is, day 25 of the experiment, hydrogen concentrations in the mucosa of stomach, duodenum, jejunum, ileum, colon, and caecum are presented in Figure 1. 
Results showed that stomach and duodenum in the MC + HRW group had the highest hydrogen levels among the four groups $(p<0.05)$, while no difference was found among the other three groups $(p>0.05)$. No difference was found in the jejunum and ileum hydrogen concentrations among the four groups $(p>0.05)$. Fusarium mycotoxin-contaminated diet was found to reduce the hydrogen levels in the caecum $(p<0.05)$, but have no impact on the hydrogen levels in the colon $(p>0.05)$. Interestingly, both LAC and HRW treatments significantly increased the hydrogen levels either in the colon or caecum when they compared with the MC group $(p<0.05)$. Furthermore, the MC + LAC group had higher hydrogen levels than the MC + HRW group in the colon and caecum samples $(p<0.05)$.

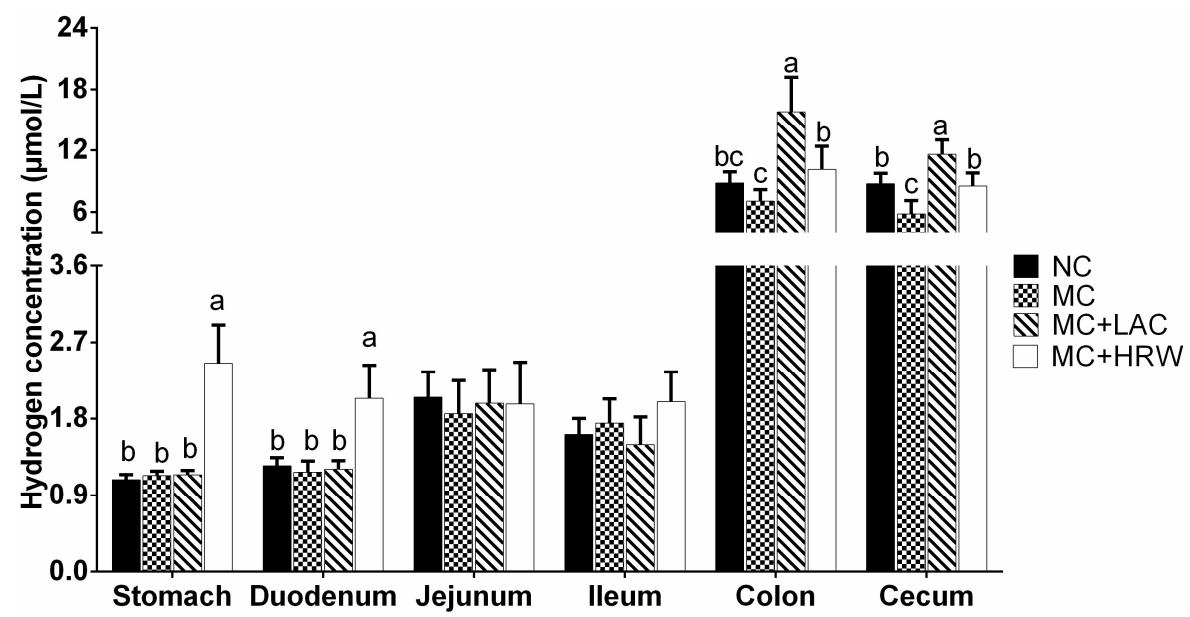

Figure 1. Effects of hydrogen-rich water and lactulose on hydrogen concentrations in different intestinal segments of female piglets fed a Fusarium mycotoxin-contaminated diet. Each column represents the mean hydrogen levels with five independent replications, mean $\pm \mathrm{SD}$. Letters a-c above the bars indicate statistical significance $(p<0.05)$ among the four treatments. NC (negative control), basal diet; MC, Fusarium mycotoxin-contaminated diet; MC + LAC, MC diet + lactulose treatment; and MC + HRW, MC diet + hydrogen-rich water treatment.

\subsection{Fecal Scoring and Diarrhea Rate}

The effects of HRW and LAC on fecal scoring and diarrhea rate in piglets fed a Fusarium mycotoxin-contaminated diet are shown in Table 1 . From days 0 to 7 and days 7 to 14 , the Fusarium mycotoxin diet was found to significantly increase the fecal score $(p<0.05)$, while HRW and LAC treatments lowered the fecal score from days 0 to 7 and days 7 to 14 , respectively $(p<0.05)$. From days 14 to 21 , days 21 to 25 , and days 0 to 25 , no significant difference was found on fecal scoring among the four groups $(p>0.05)$. No difference was found on the diarrhea rate from different time periods except from days 0 to 7 ( $p>0.05)$. Compared with the NC group, the diarrhea rate was significantly increased in both MC and MC + LAC from days 0 to $7(p<0.05)$, while HRW treatment decreased the diarrhea rate compared with the $\mathrm{MC}$ group $(p<0.05)$. Additionally, there was no difference between the $\mathrm{MC}$ and MC + LAC groups $(p>0.05)$.

Table 1. Effects of hydrogen-rich water and lactulose on fecal scoring and diarrhea rate of female piglets fed a Fusarium mycotoxin-contaminated diet ${ }^{1,2}$.

\begin{tabular}{ccccccc}
\hline Item & NC & MC & MC + LAC & MC + HRW & SEM & $p$-Value \\
\hline \multicolumn{7}{c}{ Fecal score } \\
\hline Days 0-7 & $2.64^{\mathrm{c}}$ & $3.60^{\mathrm{a}}$ & $3.17^{\mathrm{b}}$ & $2.64^{\mathrm{c}}$ & 0.10 & $<0.001$ \\
Days 7-14 & $2.84^{\mathrm{b}}$ & $3.74^{\mathrm{a}}$ & $3.12^{\mathrm{b}}$ & $3.02^{\mathrm{b}}$ & 0.12 & 0.037 \\
Days 14-21 & 2.78 & 3.00 & 2.82 & 2.95 & 0.11 & 0.909 \\
Days 21-25 & 2.79 & 2.53 & 2.82 & 3.00 & 0.15 & 0.758 \\
Days 0-25 & 2.76 & 3.30 & 3.02 & 2.91 & 0.09 & 0.163 \\
\hline
\end{tabular}


Table 1. Cont.

\begin{tabular}{ccccccc}
\hline Item & NC & MC & MC + LAC & MC + HRW & SEM & $p$-Value \\
\hline \multicolumn{7}{c}{ Diarrhea rate \% } \\
\hline Days 0-7 & $5.00^{\mathrm{b}}$ & $30.00^{\mathrm{a}}$ & $25.00^{\mathrm{a}}$ & $5.00^{\mathrm{b}}$ & 3.64 & 0.008 \\
Days 7-14 & 5.00 & 30.00 & 22.50 & 15.00 & 5.00 & 0.353 \\
Days 14-21 & 7.50 & 17.50 & 15.00 & 12.50 & 5.09 & 0.927 \\
Days 21-25 & 12.00 & 0.00 & 12.00 & 16.00 & 5.53 & 0.788 \\
Days 0-25 & 6.92 & 22.31 & 20.00 & 12.31 & 3.65 & 0.449 \\
\hline
\end{tabular}

a,b,c Values with different letters within the same row are different $(p<0.05) .{ }^{1} \mathrm{NC}$ (negative control), basal diet; MC, Fusarium mycotoxin-contaminated diet; MC + LAC, MC diet + lactulose treatment; and MC + HRW, MC diet + hydrogen-rich water treatment. ${ }^{2} n=5$.

\subsection{Short-Chain Fatty Acids (SCFAs) Levels in the Digesta of Jejumun, Ileum, Colon, and Caecum}

There was no difference $(p>0.05)$ in the $\mathrm{pH}$ value of different intestine segments among the four groups (Table S1). The concentrations of SCFAs levels in different intestinal segments among the treatments are shown in Table 2. In the jejunum and ileum, the levels of acetate, propionate, butyrate, and total SCFAs were found to be no different among the four groups $(p>0.05)$. In the colon, the acetate levels were not influenced by treatments $(p>0.05)$, but the propionate, butyrate, valeric acid, and total SCFAs concentrations in the MC group were lower than the NC group $(p<0.05)$. Compared with the MC group, HRW treatment had higher levels of butyrate $(p<0.05)$ and no effects on colon propionate, valeric acid, and total SCFAs status $(p>0.05)$. However, LAC administration significantly increased the levels of propionate, butyrate, valeric acid, and total SCFAs $(p<0.05)$ when they compared with the MC group. In the caecum, the Fusarium mycotoxin-contaminated diet significantly reduced the concentrations of acetate, propionate, butyrate, valeric acid, and total SCFAs $(p<0.05)$. Compared with the MC group, the LAC group had higher concentrations of acetate, propionate, butyrate, and total SCFAs $(p<0.05)$, and the HRW group had higher levels of acetate, butyrate, and total SCFAs $(p<0.05)$.

Table 2. Effects of hydrogen-rich water and lactulose on short-chain fatty acids (SCFAs) profiles in the jejunum, ileum, colon, and caecum digesta of female piglets fed a Fusarium mycotoxin-contaminated $\operatorname{diet}^{1,2}$

\begin{tabular}{|c|c|c|c|c|c|c|}
\hline Item & NC & MC & MC + LAC & MC + HRW & SEM & $p$-Value \\
\hline \multicolumn{7}{|c|}{ Jejunum ( $\mu \mathrm{mol} / \mathrm{g}$ wt digesta) } \\
\hline Acetate & 4.30 & 3.80 & 4.48 & 4.14 & 0.27 & 0.819 \\
\hline Propionate & 2.08 & 1.58 & 1.83 & 1.99 & 0.12 & 0.486 \\
\hline Butyrate & 0.94 & 0.72 & 0.84 & 1.00 & 0.06 & 0.425 \\
\hline Total SCFAs & 7.45 & 6.10 & 7.15 & 7.13 & 0.43 & 0.737 \\
\hline \multicolumn{7}{|c|}{ Ileum ( $\mu \mathrm{mol} / \mathrm{g}$ wt digesta) } \\
\hline Acetate & 10.50 & 10.64 & 10.58 & 10.29 & 0.41 & 0.993 \\
\hline Propionate & 5.09 & 5.56 & 5.65 & 5.16 & 0.27 & 0.660 \\
\hline Butyrate & 0.49 & 0.50 & 0.52 & 0.54 & 0.03 & 0.932 \\
\hline Total SCFAs & 16.08 & 16.69 & 16.75 & 15.99 & 0.66 & 0.971 \\
\hline \multicolumn{7}{|c|}{ Colon ( $\mu \mathrm{mol} / \mathrm{g}$ wt digesta) } \\
\hline Acetate & 44.28 & 39.83 & 49.94 & 43.78 & 1.48 & 0.102 \\
\hline Propionate & $19.13^{\mathrm{a}}$ & $11.19^{b}$ & $20.13^{\mathrm{a}}$ & $14.62^{\mathrm{ab}}$ & 1.17 & 0.010 \\
\hline Butyrate & $8.25^{\mathrm{a}}$ & $4.00^{\mathrm{b}}$ & $7.55^{\mathrm{a}}$ & $7.35^{\mathrm{a}}$ & 0.53 & 0.008 \\
\hline Valeric acid & $4.40^{\mathrm{a}}$ & $1.00^{\mathrm{c}}$ & $2.55^{\mathrm{b}}$ & $0.91^{\mathrm{c}}$ & 0.40 & $<0.001$ \\
\hline Total SCFAs & $76.06^{\mathrm{a}}$ & $56.02^{b}$ & $80.18^{a}$ & $66.66^{\mathrm{ab}}$ & 2.99 & 0.008 \\
\hline
\end{tabular}


Table 2. Cont.

\begin{tabular}{ccccccc}
\hline Item & NC & MC & MC + LAC & MC + HRW & SEM & $p$-Value \\
\hline \multicolumn{7}{c}{ Caecum $(\mu$ mol/g wt digesta $)$} \\
\hline Acetate & $57.29^{\mathrm{a}}$ & $51.47^{\mathrm{b}}$ & $60.45^{\mathrm{a}}$ & $60.91^{\mathrm{a}}$ & 1.14 & 0.003 \\
Propionate & $26.20^{\mathrm{a}}$ & $19.12^{\mathrm{b}}$ & $25.97^{\mathrm{a}}$ & $22.50^{\mathrm{ab}}$ & 0.99 & 0.020 \\
Butyrate & $12.43^{\mathrm{a}}$ & $6.02^{\mathrm{c}}$ & $9.89^{\mathrm{b}}$ & $10.04^{\mathrm{b}}$ & 0.59 & $<0.001$ \\
Valeric acid & $9.84^{\mathrm{a}}$ & $2.49^{\mathrm{b}}$ & $2.22^{\mathrm{b}}$ & $3.01^{\mathrm{b}}$ & 0.77 & $<0.001$ \\
Total SCFAs & $105.76^{\mathrm{a}}$ & $79.10^{\mathrm{c}}$ & $98.53^{\mathrm{ab}}$ & $96.46^{\mathrm{b}}$ & 2.60 & $<0.001$ \\
\hline
\end{tabular}

$\mathrm{a}, \mathrm{b}, \mathrm{c}$ Values with different letters within the same row are different $(p<0.05) .{ }^{1} \mathrm{NC}$ (negative control), basal diet; MC, Fusarium mycotoxin-contaminated diet; MC + LAC, MC diet + lactulose treatment; and MC + HRW, MC diet + hydrogen-rich water treatment. ${ }^{2} n=5$.

\subsection{Microbiota Communities of Total Bacteria and Methanogenic Archaea in the Digesta of Intestinal Segments}

Representative DGGE analysis of total bacteria in foregut (jejunum and ileum) and hindgut (colon and caecum) are shown in Figure 2A,C and Figure 3A,C, respectively. DGGE profiles of PCR products in the V6-V8 regions of the 16S rRNA gene from the four groups revealed some difference among different treatments at the foregut and hindgut. It is shown that jejunum (Figure 2A), ileum (Figure 2C), and colon (Figure 3A) amplicons migrating to the top of the gel were predominant in the samples of all groups, and caecum amplicons (Figure $3 \mathrm{C}$ ) migrating to the middle of the gel were predominant in the samples of all treatment.
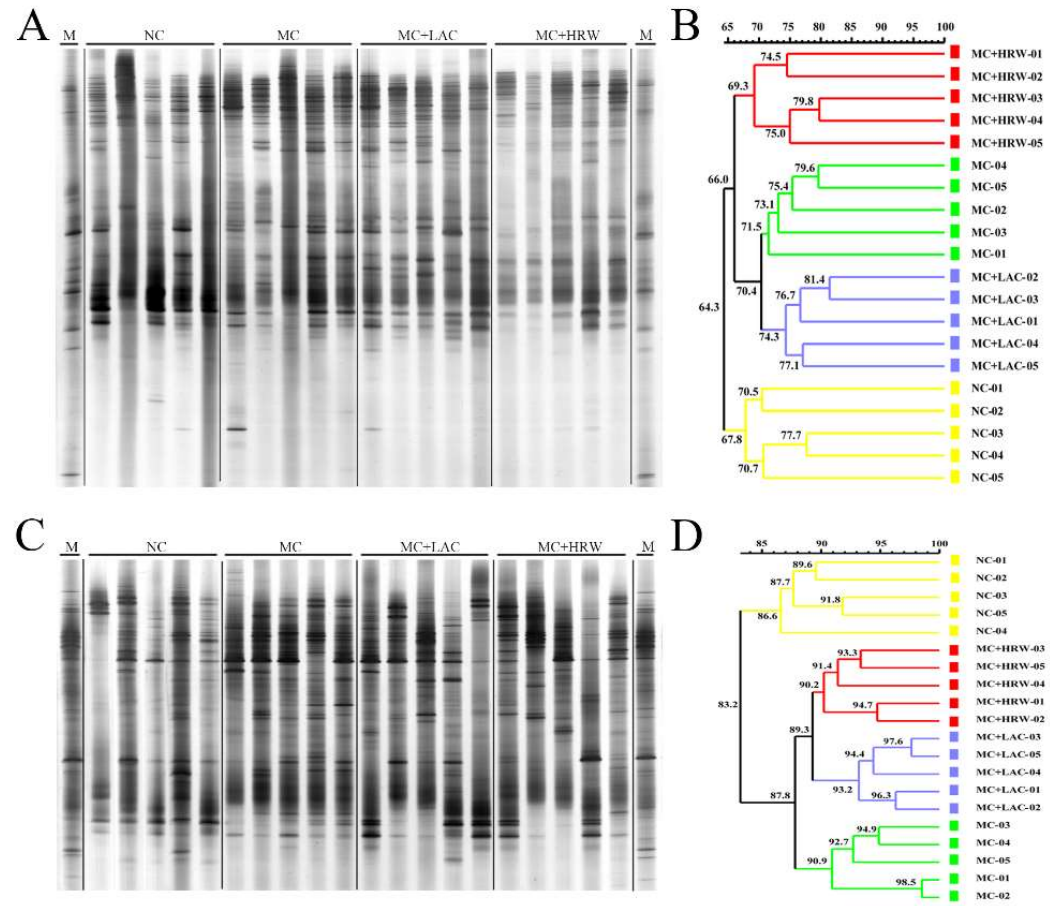

Figure 2. Effects of hydrogen-rich water and lactulose on jejunum and ileum digesta PCR-DGGE profiles of V6-V8 amplicons and similarities index of female piglets fed a Fusarium mycotoxin-contaminated diet. (A) DGGE profile of bacteria community in the jejunum digesta of four groups; (B) Similarity index of bacteria DGGE profile obtained from jejunum digesta of four groups; (C) DGGE profile of bacteria community in the ileum digesta of four groups; (D) Similarity index of bacteria DGGE profile obtained from ileum digesta of four groups. NC (negative control), basal diet; MC, Fusarium mycotoxin-contaminated diet; MC + LAC, MC diet + lactulose treatment; and MC + HRW, MC diet + hydrogen-rich water treatment. 
A

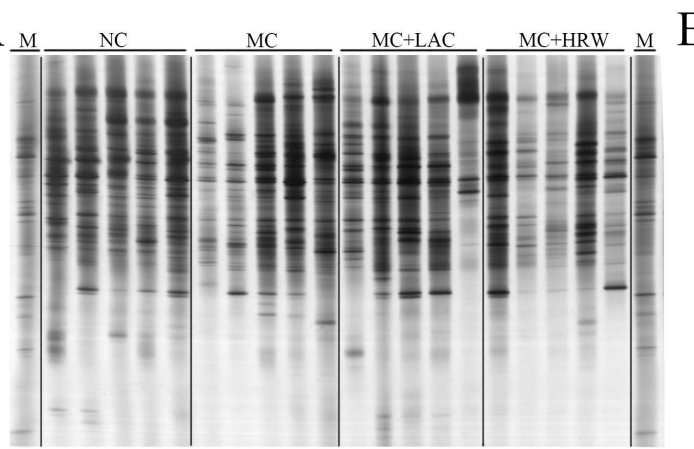

$\mathrm{C}$

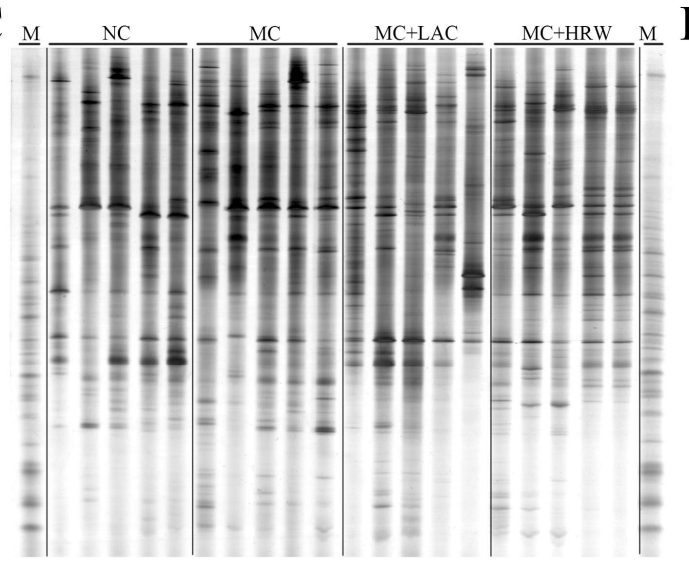

B

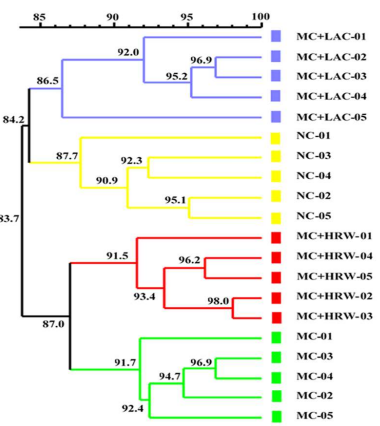

$\mathrm{D}$

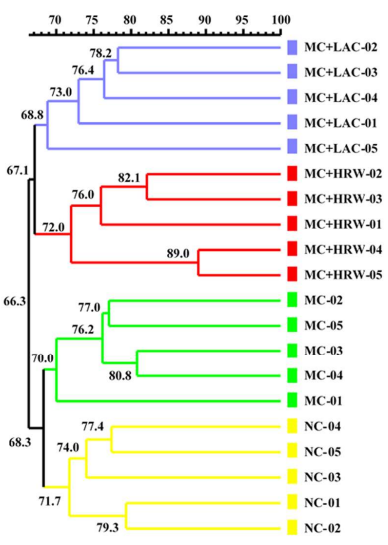

Figure 3. Effects of hydrogen-rich water and lactulose on colon and caecum digesta PCR-DGGE profiles of V6-V8 amplicons and similarities index of female piglets fed a Fusarium mycotoxin-contaminated diet. (A) DGGE profile of bacteria community in the colon digesta of four groups; (B) Similarity index of bacteria DGGE profile obtained from colon digesta of four groups; (C) DGGE profile of bacteria community in the caecum digesta of four groups; (D) Similarity index of bacteria DGGE profile obtained from caecum digesta of four groups. NC (negative control), basal diet; MC, Fusarium mycotoxins-contaminations diet; MC + LAC, MC diet + lactulose treatment; and MC + HRW, MC diet + hydrogen-rich water treatment.

Cluster analysis revealed that the overall similarity of total bacteria DGGE patterns in the jejunum, ileum, colon, and caecum were $64.3 \%, 83.2 \%, 83.7 \%$, and 66.3\%, respectively (Figure 2B,D, Figure 3B,D, respectively). In the jejunum and ileum, the $\mathrm{NC}$ group samples formed in one cluster with a similarity of $67.8 \%$ and $86.6 \%$, while MC, MC + LAC, and MC + HRW groups were in another cluster with a similarity of $66.0 \%$ and $87.8 \%$, respectively. In the colon, NC and MC + HRW groups formed in one cluster with $84.2 \%$ similarity, and MC formed another cluster with the MC + LAC group. However, the cluster pattern in the caecum was quite different, in which NC and MC groups were found in one coherent cluster with $68.3 \%$ similarity, and MC + LAC with MC + HRW groups formed another cluster with $67.1 \%$ similarity.

For the methanogenic Archaea compositions, the ileum (Figure 4A), colon (Figure 4C), and caecum (Figure 4E) amplicons migrating to the top of gels were predominant in the samples of all groups. DGGE cluster analysis showed that the overall similarity in the ileum, colon, and caecum were $39.7 \%$, $83.7 \%$, and $43.0 \%$, respectively. In the ileum (Figure $4 \mathrm{~B}$ ), the NC group formed one cluster with a similarity of $44.1 \%$, while MC, MC + LAC, and MC + HRW groups formed another cluster with a similarity of $43.6 \%$. In the colon (Figure 4D), the methanogenic Archaea pattern is different than the ileum, in which NC and MC + LAC treatments formed one cluster with $84.2 \%$ similarity, while MC and $\mathrm{MC}+\mathrm{HRW}$ groups formed another cluster with $87.2 \%$ similarity. In the caecum (Figure $4 \mathrm{~F}$ ), the NC group formed one cluster with $58.3 \%$ similarity. Except for one sample from the MC + LAC group, the MC, MC + HRW, and MC + LAC groups formed another cluster with 55.1\% similarity. 
A

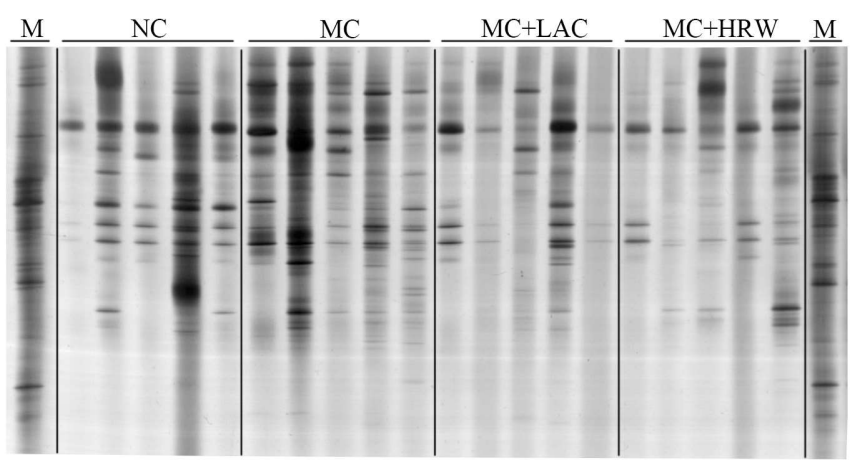

$\mathrm{C}$

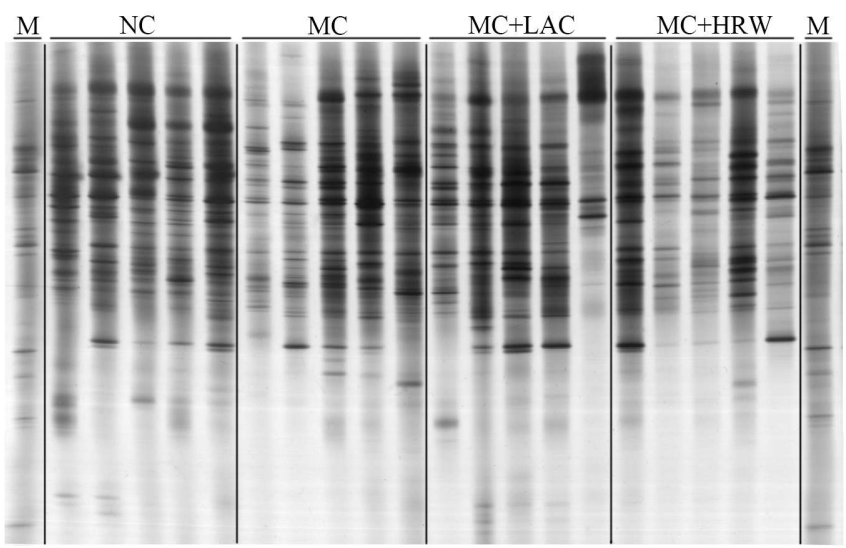

E

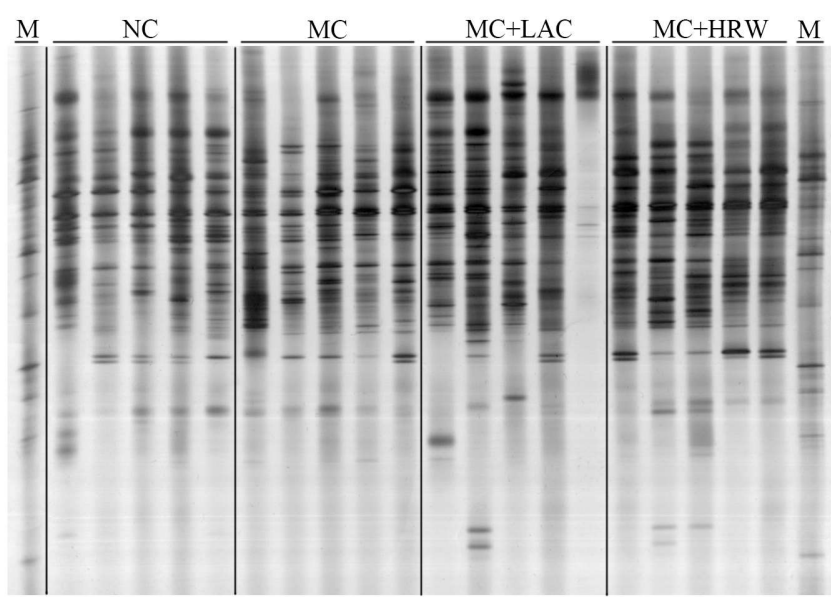

$\mathrm{B}$

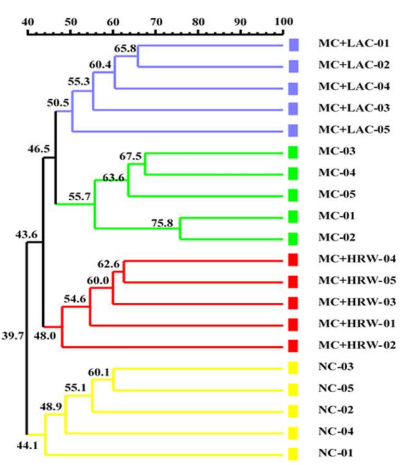

$\mathrm{D}$

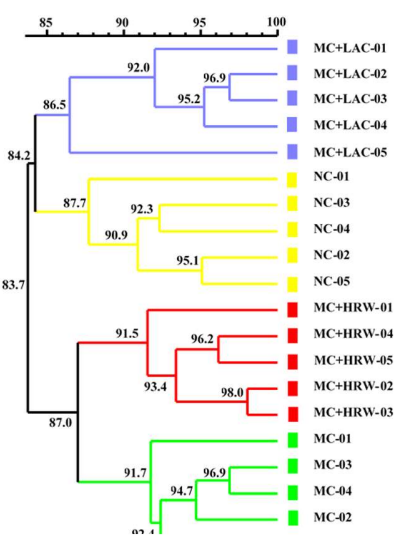

$\mathrm{F}$

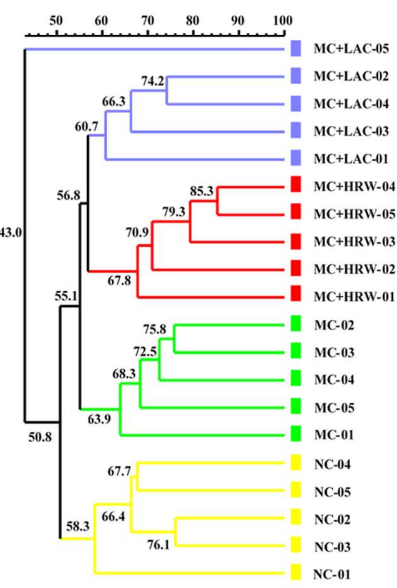

Figure 4. Effects of hydrogen-rich water and lactulose on the ileum, colon and caecum digesta PCR-DGGE profiles of methanogenic Archaea and the similarities index of female piglets fed a Fusarium mycotoxin-contaminated diet. (A) DGGE profile of methanogenic Archaea community in the ileum digesta of four groups; (B) Similarity index of methanogenic Archaea DGGE profile obtained from ileum digesta of four groups; (C) DGGE profile of methanogenic Archaea community in the colon digesta of four groups; (D) Similarity index of methanogenic Archaea DGGE profile obtained from colon digesta of four groups; (E) DGGE profile of methanogenic Archaea community in the caecum digesta of four groups; (F) Similarity index of methanogenic Archaea DGGE profile obtained from caecum digesta of four groups. NC (negative control), basal diet; MC, Fusarium mycotoxins-contaminations diet; MC + LAC, MC diet + lactulose treatment; and MC + HRW, MC diet + hydrogen-rich water treatment.

The band number and Shannon diversity index of total bacteria and methanogenic Archaea were also analyzed and are shown in Table 3. For total bacteria, the band numbers and Shannon diversity in the jejunum were not affected by treatments $(p>0.05)$. In the ileum, Fusarium mycotoxins did 
not affect the band numbers $(p>0.05)$, but MC + LAC group had more band numbers than the MC group $(p<0.05)$. The Shannon diversity was found to be significantly increased by Fusarium mycotoxin treatment, while neither LAC nor HRW influenced the Shannon diversity $(p>0.05)$. In the colon, Shannon diversity found no differences among the treatments $(p>0.05)$. MC and MC $+\mathrm{LAC}$ groups were found to have higher band numbers than the NC and MC + HRW groups $(p<0.05)$, and no difference was found neither between the MC and MC + LAC groups nor between the NC and $\mathrm{MC}+\mathrm{HRW}$ groups $(p>0.05)$. In the caecum, Shannon diversity did not find any differences among the four groups. Band numbers in the MC, MC + LAC, and MC + HRW groups were significantly higher than the NC group $(p>0.05)$, while no difference was found among the MC, MC $+\mathrm{LAC}$, and $\mathrm{MC}+\mathrm{HRW}$ groups $(p<0.05)$.

Table 3. Effects of hydrogen-rich water and lactulose on the number of DGGE bands and Shannon diversity of the jejunum, ileum, colon, and caecum digesta of female piglets fed a Fusarium mycotoxin-contaminated diet ${ }^{1,2}$.

\begin{tabular}{|c|c|c|c|c|c|c|c|c|}
\hline Target Group & DNA Sample & Item & NC & MC & MC + LAC & MC + HRW & SEM & $p$-Value \\
\hline \multirow{8}{*}{ Total bacteria } & \multirow{2}{*}{ Jejunum } & Band number & 59.20 & 60.60 & 64.60 & 59.60 & 1.34 & 0.498 \\
\hline & & Shannon diversity & 3.40 & 3.64 & 3.68 & 3.60 & 0.05 & 0.278 \\
\hline & \multirow[t]{2}{*}{ Ileum } & Band number & $34.40^{c}$ & $37.70^{b c}$ & $44.40^{\mathrm{a}}$ & $38.40^{\mathrm{b}}$ & 1.00 & $<0.001$ \\
\hline & & Shannon diversity & $3.00^{\mathrm{b}}$ & $3.27^{\mathrm{a}}$ & $3.49^{\mathrm{a}}$ & $3.34^{\mathrm{a}}$ & 0.06 & 0.006 \\
\hline & \multirow[t]{2}{*}{ Colon } & Band number & $40.00^{\mathrm{b}}$ & $50.40^{a}$ & $52.00^{\mathrm{a}}$ & $40.00^{b}$ & 1.60 & 0.001 \\
\hline & & Shannon diversity & 3.14 & 3.15 & 3.14 & 3.19 & 0.04 & 0.948 \\
\hline & \multirow[t]{2}{*}{ Caecum } & Band number & $61.60^{\mathrm{b}}$ & $72.60^{a}$ & $72.80^{\mathrm{a}}$ & $71.60^{a}$ & 4.23 & 0.036 \\
\hline & & Shannon diversity & 3.55 & 3.76 & 3.75 & 3.81 & 0.04 & 0.070 \\
\hline \multirow{6}{*}{ Methanogens } & \multirow[t]{2}{*}{ Ileum } & Band number & $15.20^{\mathrm{b}}$ & $26.80^{a}$ & $17.20^{\mathrm{b}}$ & $18.40^{\mathrm{b}}$ & 1.14 & $<0.001$ \\
\hline & & Shannon diversity & $2.27^{b}$ & $2.91^{\mathrm{a}}$ & $2.27^{\mathrm{b}}$ & $2.28^{\mathrm{b}}$ & 0.09 & 0.015 \\
\hline & \multirow[t]{2}{*}{ Colon } & Band number & $29.80^{b c}$ & $36.20^{\mathrm{a}}$ & $32.20^{\mathrm{b}}$ & $27.40^{c}$ & 0.89 & $<0.001$ \\
\hline & & Shannon diversity & 2.99 & 3.23 & 2.87 & 2.89 & 0.07 & 0.208 \\
\hline & \multirow[t]{2}{*}{ Caecum } & Band number & $31.40^{\mathrm{b}}$ & $41.00^{\mathrm{a}}$ & $32.80^{\mathrm{b}}$ & $34.60^{b}$ & 1.27 & 0.023 \\
\hline & & Shannon diversity & 3.06 & 3.34 & 2.92 & 3.22 & 0.08 & 0.234 \\
\hline
\end{tabular}

a,b,c Values with different letters within the same row are different $(p<0.05) .{ }^{1} \mathrm{NC}$ (negative control), basal diet; $\mathrm{MC}$, Fusarium mycotoxin-contaminated diet; MC + LAC, MC diet + lactulose treatment; and MC + HRW, MC diet + hydrogen-rich water treatment. ${ }^{2} n=5$.

For methanogenic Archaea, the band number from the ileum, colon, and caecum digesta in the MC group were significantly higher than the NC group $(p<0.05)$, and both LAC and HRW were found to reduce those band number compared with MC group $(p<0.05)$. The Shannon diversity of ileum digesta in the MC group was significantly higher than the NC group $(p<0.05)$, and MC + LAC and $\mathrm{MC}+\mathrm{HRW}$ were found to have lower Shannon diversity than the MC group $(p<0.05)$. The Shannon diversity of colon and caecum digesta showed no significant differences among the four groups $(p>0.05)$.

\subsection{Populations of Selected Bacteria in the Digesta of Different Intestinal Segments}

Table 4 shows the populations of selected microbiota in the digesta of the jejunum, ileum, colon, and caecum in piglets fed a Fusarium mycotoxin-contaminated diet. In the jejunum and caecum, no difference was found on the abundance of selected bacteria among the four treatments $(p>0.05)$. In the ileum, the populations of total bacteria, Lactobacillus, and Enterococcus were not impacted by treatments, but the abundance of $E$. coli in the MC group was higher than NC, MC + LAC, and MC + HRW groups $(p<0.05)$. The MC group also had a lower $(p<0.05)$ Bifidobacterium abundance than the NC, MC + LAC, and MC + HRW groups, while no difference was found among the latter three groups $(p>0.05)$. In the colon, the populations of total bacteria and acetogenic bacteria showed no significant difference among the four groups $(p>0.05)$. However, the abundance of methanogenic Archaee and sulfate-reducing bacteria (SRB) was lower in the MC group than the NC group $(p<0.05)$. In addition, $\mathrm{MC}+\mathrm{HRW}$ and $\mathrm{MC}+\mathrm{LAC}$ groups were found to have higher populations of these two selected species than the MC group $(p<0.05)$. 
Table 4. Effects of hydrogen-rich water and lactulose on the populations (log copies number/g) of selected bacteria in the digesta of the jejunum, ileum, colon and caecum of female piglets fed a Fusarium mycotoxin-contaminated diet ${ }^{1,2}$.

\begin{tabular}{cccccccc}
\hline Sample & Item & NC & MC & MC + LAC & MC + HRW & SEM & $p$-Value \\
\hline Jejunum & All bacteria & 8.75 & 8.66 & 8.67 & 8.20 & 0.13 & 0.486 \\
& Lactobacillus & 7.96 & 7.43 & 7.25 & 7.28 & 0.19 & 0.552 \\
& Bifidobacterium & 4.90 & 4.76 & 5.26 & 5.14 & 0.08 & 0.124 \\
& Escherichia coli & 4.87 & 5.78 & 5.53 & 5.31 & 0.14 & 0.127 \\
& Enterococcus & 3.30 & 3.45 & 3.21 & 3.06 & 0.11 & 0.685 \\
\hline Ileum & All bacteria & 9.04 & 9.64 & 9.43 & 9.53 & 0.14 & 0.221 \\
& Lactobacillus & 8.85 & 8.60 & 8.75 & 8.86 & 0.25 & 0.906 \\
& Bifidobacterium & $5.07^{\mathrm{a}}$ & $4.23^{\mathrm{b}}$ & $5.26^{\mathrm{a}}$ & $5.13^{\mathrm{a}}$ & 0.13 & 0.009 \\
& Escherichia coli & $5.67^{\mathrm{b}}$ & $7.25^{\mathrm{a}}$ & $6.14^{\mathrm{b}}$ & $6.21^{\mathrm{b}}$ & 0.16 & 0.005 \\
& Enterococcus & 3.08 & 3.66 & 3.39 & 3.32 & 0.58 & 0.488 \\
\hline Colon & All bacteria & 11.04 & 11.09 & 11.17 & 10.93 & 0.07 & 0.704 \\
& Methanogens & $4.49^{\mathrm{a}}$ & $3.47^{\mathrm{c}}$ & $5.52^{\mathrm{a}}$ & $4.58^{\mathrm{b}}$ & 0.20 & 0.001 \\
& SRB ${ }^{3}$ & $4.54^{\mathrm{a}}$ & $3.27^{\mathrm{b}}$ & $4.68^{\mathrm{a}}$ & $4.12^{\mathrm{a}}$ & 0.18 & 0.011 \\
& Acetogenic bacteria & 6.87 & 6.85 & 7.17 & 6.54 & 0.11 & 0.297 \\
\hline Caecum & All bacteria & 11.57 & 11.34 & 11.69 & 11.60 & 0.05 & 0.119 \\
& Methanogens & 5.14 & 5.55 & 5.44 & 5.36 & 0.28 & 0.969 \\
& SRB ${ }^{3}$ & 2.89 & 3.39 & 3.02 & 2.88 & 0.12 & 0.470 \\
& Acetogenic bacteria & 6.21 & 6.31 & 6.32 & 6.19 & 0.16 & 0.992 \\
\hline
\end{tabular}

a,b,c Values with different letters within the same row are different $(p<0.05) .{ }^{1} \mathrm{NC}$ (negative control), basal diet; MC, Fusarium mycotoxin-contaminated diet; MC + LAC, MC diet + lactulose treatment; and MC + HRW, MC diet + hydrogen-rich water treatment. ${ }^{2} n=5 .{ }^{3} \mathrm{SRB}=$ Sulfate-reducing bacteria.

\section{Discussion}

The gut microbiota ecological system represents an abundant community of organisms, including bacteria, archaea, fungi, and viruses, that colonized within the GI tract [20]. The complex and large diverse communities of the microbiota play important roles in nutrition decomposition and transformation, immunity intrusion, and gut villous structure development through a symbiotic relationship with the host [20]. Diet is a major factor that influences the makeup and activity of colonized microbes in the intestinal gut, and we had hypothesized that Fusarium mycotoxins could induce compositions and/or metabolites changes in the gut microbiota, and eventually affect the health of female piglets. In addition, oral HRW or lactulose administrations may partly spare the harmful activity of Fusarium mycotoxins on the intestinal microbiota ecosystem of female weaning piglets. These results partly support our hypothesis.

\subsection{Hydrogen Levels in Intestinal Segments}

One major function of microbiota in the gut lumen is the fermentation of indigestible polysaccharides, dietary fiber, and resistant starch, which generates large quantities of $\mathrm{H}_{2}$ [21]. In this study, our data showed that administration of HRW increased concentrations of $\mathrm{H}_{2}$ in the stomach, duodenum, colon, and caecum. However, lactulose treatment was found to have no impact on the $\mathrm{H}_{2}$ levels in the foregut, but significantly increased the concentrations of $\mathrm{H}_{2}$ in the hindgut (colon and caecum). The communities, species, and population of microbiota in the hindgut were more complex than the foregut and might contribute to this difference [22]. In fact, these observed $\mathrm{H}_{2}$ concentrations in the intestine were similar to those in a study reported by Liu et al. [23], who recently developed a conventional gas chromatography method to measure the hydrogen levels in the tissue following administration of HRW, hydrogen-rich saline and inhalation of hydrogen gas at different time points. Their data indicated that after $30 \mathrm{~min}$ of administration, hydrogen gas could also be detected at around 10-20 ppb/g intestine tissue. Moreover, oral administration of HRW had the highest Cmax compared with other methods [23]. Watanabe et al. found that inhalation of hydrogen gas 
resulted in slower elevation than that achieved with intraperitoneal administration [24], indicating that different administration ways of providing hydrogen may result in different hydrogen distributions in blood and tissues. On the other hand, previous studies also indicated that oral administration of hydrogen-rich water/saline had very short lasting time [25]. Thus, the protective effects of HRW in this study may not yet be fully exerted. Therefore, the search for an ideal hydrogen-producing prebiotic may be an interesting method to solve this concern.

Lactulose is a semisynthetic disaccharide and cannot be metabolized nor absorbed in the intestine [15]. Like other polysaccharides, lactulose is fermented in the gastrointestinal gut by bacteria, producing SCFAs. Hydrogen gas is one of its metabolites, which may act as an effective ideal agent [26]. A higher breath $\mathrm{H}_{2}$ can be detected after oral administration of lactulose [17]. After lactulose administration, the exhaled breath $\mathrm{H}_{2}$ concentration was found to be increased after 15 min and reaching a peak at 45 min in mice; meanwhile, lactulose with antibiotic treatment did not find an improvement of breath hydrogen levels [27]. On one hand, a proportion of hydrogen gas may pass through the gut mucosa wall into the blood and be transported to other organs. On the other hand, hydrogen also can be metabolized by intestinal microbiota. Yu et al. also demonstrated that lactulose significantly increased the accumulated hydrogen levels, and antibiotic administration induced a smaller amount of $\mathrm{H}_{2}$ in rats [16]. These results indicate that bacterial fermentation may play a curial role in the beneficial effects of lactulose in animals. Considering the features of LAC, it is broadly in line with our expectations that lactulose administration had a continual improvement in the hydrogen concentrations in the mucosa of the hindgut (colon and caecum). Although higher hydrogen levels were both observed in HRW (stomach and duodenum) and LAC (colon and caecum) treatments compared with MC group, it is not representative of all $\mathrm{H}_{2}$ production of HRW or LAC. Thus, more research needs to be carried out to demonstrate the dynamic changes of hydrogen gas in the intestine after receiving hydrogen-rich water or lactulose in piglets.

\subsection{Fecal Scoring and Diarrhea Rate}

Disruptions of the microbiota ecological system under abnormal conditions is recognized as a major risk factor for various diseases, such as diarrhea and inflammatory bowel disease. In the swine industry, weaning piglets face enormous stress, leading to perturbations in gut microbiota, and host physiological and mucosal immune function, such as microbiological, environmental, and dietary factors. The transition from liquid to solid feeding is expected to result in decreased feed intake and daily weight gain, and increased diarrhea incidence [28]. Corn and soybean meal represent over $50 \%$ of the total dietary ingredients, which are often contaminated with mycotoxins [29]. Thus, post-weaning piglets are always associated with diarrhea or loose feces [30]. Consumption of DONand ZEN-contaminated feeds will induce intoxication symptoms, including vomiting, abdominal distress, malaise, diarrhea emesis, and even shock or death [3]. In the present study, lower feed intake and weight gain [31], fever, and severe diarrhea were observed in piglets fed a Fusarium mycotoxin-contaminated diet. A lower fecal score has been considered a good indicator of gut health [32]. Feces scoring was decreased in piglets fed a Fusarium mycotoxin-contaminated diet in the critical period of days 0 to 7 and days 7 to 14 after weaning. In addition, the MC group had higher diarrhea rates than the NC group in the first week. These results are consistent with previous studies in which DON has the capacity to increase intestinal permeability, and cause microbiota dysfunctions which promote intestinal disorders [3,33]. It is also reported that DON ingestion was associated with the reduction of mRNA expression of $\mathrm{Na}^{+}$-dependent glucose transport sodium-dependent glucose cotransporter 1 (SGLT1) [34]. Since SGLT1 is responsible for water reabsorption, inhibition of SGLT1 could also cause diarrhea, which might be the underlying cause of diarrhea in animals exposed to mycotoxins [34].

A number of studies have demonstrated that prebiotics may selectively increase the population and/or activity of beneficial bacteria [35], decreasing the incidence of diarrhea. Lactulose is always used in the treatment of constipation and hepatic encephalopathy in humans [15]. However, at low 
doses, lactulose acts as a prebiotic that improves growth performance and intestinal morphology in pigs [36]. A previously study on piglets showed that 1\% lactulose supplementation had higher growth performance [37]. Additionally, our previous study also suggested that lactulose could improve anti-oxidant capacity of piglets fed a mycotoxin-contaminated diet [31]. Although no studies explored the effects of HRW on diarrhea, a protective effect of HRW was found on DSS-induced inflammatory bowel disease (IBD) in rats, and intestinal villi damage in mice [10]. The exact mechanisms underlying the protective effects of HRW and LAC on diarrhea is still unclear, but might be attributed to the ability of both HRW and lactulose could remedy mycotoxin-induced intestine damage through the anti-oxidant and anti-inflammatory properties. Therefore, it is not surprising that piglets orally administered HRW or lactulose had a lower fecal score and incidence of diarrhea than the MC group.

\subsection{SCFAs Levels in the Digesta of Jejumun, Ileum, Colon, and Caecum}

Shifting of the microbiota composition and quality of intestinal microbiota, followed by the alternation in SCFAs levels and other metabolites, may have a role in ensuring animal health and disease [38]. Here, we found a significant inhibitory effect of Fusarium mycotoxins on the production of SCFAs in the colon and caecum, which have not been previously reported. Ingestion of DON contaminated diet was found to significantly reduce feed intake and increase diarrhea [3], which would increase the water levels and reduce the dry matter content in the digesta. In fact, compared with the NC group, a lower caecum relative weight was observed in the MC group (Figure S1). Therefore, it is conceivable that Fusarium mycotoxins (DON and ZEN) may have modified the microbiota fermentation in the hindgut due to changes in the colon and caecum nutrient flow and water content. In addition, the hydrogen levels in the hindgut were also reduced by Fusarium mycotoxin treatment, which may support the changes of SCFAs production.

As a prebiotic, lactulose is not broken down by mammalian intestine enzymes, but can be metabolized by gut microbiota to SCFAs. A previous study in pigs revealed that the inclusion of lactulose in the diet increased the SCFAs concentration in the large intestine [39]. Increased SCFAs concentrations were also observed in broiler chickens provided with lactulose supplementation [40]. However, Martin-Pelaez et al. found that $1 \%$ dietary lactulose supplementation did not affect caecum butyric acid concentration in piglets that were orally challenged with Salmonella [41]. Recently, it has been shown that the dietary inclusion of $1 \%$ lactulose did not change the branched-chain fatty acids (BCFA) levels in piglets [37]. Our data suggests that lactulose modified the hindgut microbiota fermentation, resulting in higher SCFAs production. So far, the relationship of hydrogen-rich water on short-chain fatty acid production in vivo and in vitro are unknown. Further studies are warranted to explore the effects of HRW and lactulose on bacteria fermentation in piglets.

\subsection{Microbiota Communities and Populations}

It is well known that the dynamic complex intestinal microbial ecosystem plays key roles in maintaining host nutritional, physiological, and immunological functions [38]. Thus, impairment of microbiota balance could have many adverse effects on the health of the host. Mycotoxins not only undergo microbial metabolism in the gastrointestinal tract, but may also affect the communities due to some toxins exhibiting antimicrobial properties [34,42]. In vitro studies showed that DON did not influence the growth of Staphylococcus aureus, E. coli, and Yersinia enterocolitica [43]. It has been reported that consumption of feed contaminated with a moderate level of DON had a slight effect on cultivable bacteria in pig intestines, and the composition of intestinal microbiota was also observed in DON-exposed animals [44]. Feeding pigs with T-2 toxin led to a substantial increase of aerobic bacterial counts in the intestine [45]. Similarly, chronic exposure of pigs to low doses of DON caused an increase in the number of intestinal aerobic bacteria and modified the dynamics of intestinal bacteria communities [6]. Piotrowska et al. also reported the effect of exposure of pigs to the Fusarium mycotoxins ZEN and DON, administered together and separately, on the colon microbiota [7]. After 42 days of experiment, their data found that ZEN alone, and together with DON, had an adverse 
effect on mesophilic aerobic bacteria. The concentration of C. perfringens, E. coli, and other bacteria in the family Enterobacteriaceae was significantly reduced by ZEN alone, and together with DON. The functional biodiversity of microorganisms was also affected by mycotoxins, which Shannon's diversity index was higher [7]. In our study, cluster results of DGGE profiles obtained from the jejunum, ileum, colon, and caecum showed that the mycotoxin-contaminated diet drastically affected the communities, diversity, and population of gastrointestinal microbiota (especially in the ileum and colon). Moreover, our data also indicated that hydrogen-utilizing bacteria (methanogenic Archaea and SRB) were also involved in the mycotoxincosis-induced intestinal microbiota dysbiosis.

Previous in vivo studies demonstrated positive protective effects of lactulose on colon fermentation [46]. Lactulose was reported to increase the number of Bifidobacteria and Lactobacilli while reducing the numbers of Clostridium spp., Salmonella spp., or E. coli in the pig gastrointestinal tract [36]. Guerra-Ordaz et al. demonstrated that lactulose significantly improved the performance and colonic microbial activity of weaning piglets [37]. In a previous study, lactulose was included in the diet at $1 \%, 0.2 \%, 0.4 \%, 0.6 \%$, or $0.8 \%$ at the expense of corn and/or soybean meal. A significant quadratic response in the Lactobacillus count was observed at 42 days on increasing the level of lactulose [40]. However, the effects of HRW on intestinal microbiota in piglets are quite limited. In a mouse study, 16S rRNA gene sequencing analysis was introduced to explore the effects of AEW on the microbial composition of C57BL/6N mice. After four weeks of treatment, the relative abundance of 20 taxa differed significantly in AEW-administered mice [47]. Xiao et al. also reported that hydrogen-water oral gavage resulted in retention of TAI-shifted intestinal bacterial composition in mice by high-throughput sequencing [14], which is consistent with our results. In the present, our data showed that both lactulose supplemental could influence the communities and diversity of bacteria and methanogenic Archaea in different segments of piglets fed a mycotoxin-contaminated diet. In addition, the shifts of the abundance of Bifidobacterium and E. coli in the ileum digesta, and hydrogen-utilizing bacteria in the colon were also attenuated by both HRW and LAC treatments.

\section{Conclusions}

In this study, we found that Fusarium mycotoxin significantly affected the metabolism, activities, and communities of gut microbiota, and eventually caused a higher diarrhea rate in female piglets. Most importantly, both hydrogen-rich water and lactulose have shown protective effects on the imbalance of intestinal microbiota, reducing the SCFAs production and the higher diarrhea rate induced by Fusarium mycotoxin-contaminated diet, partly through affecting the communities/populations of microbiota and the evaluation of hydrogen gas. These results partly support our original hypothesis.

\section{Materials and Methods}

\subsection{Preparation of Fusarium Mycotoxin-Contaminated Maize}

The Fusarium graminearum strain 2021 was cultured and conidia were prepared as previously described [48]. Commercial maize was soaked in tap water for $72 \mathrm{~h}$, and autoclaved at $121{ }^{\circ} \mathrm{C}$ for $30 \mathrm{~min}$. Then, the maize was incubated in plastic storage boxes with $1 \times 10^{6}$ conidia $/ \mathrm{kg}$ for 30 days (15-25 ${ }^{\circ} \mathrm{C}$ and $50-85 \%$ humidity). The cool autoclaved maize without conidia was used as the control maize. Finally, uncontaminated and Fusarium graminearum-contaminated maize were dried in an oven at 70 for $24 \mathrm{~h}$, respectively.

\subsection{Experimental Diets and Mycotoxins Analyusis}

Fusarium mycotoxin-contaminated maize and uncontaminated control maize were used at $44.5 \%$ at the expense of normal maize for the manufacturing of two experimental diets, respectively. The experimental diets (negative control (NC) and mycotoxin-contaminated diet (MC), respectively) were formulated according to the recommendation of the nutrient requirement of swine by the National 
Research Council [49] and based on a previous study [50] with minor modifications to the vitamin and mineral premix.

No antibiotic, hormone, and preservatives were added to the diets. Table S2 shows the ingredients of the two experimental diets used in this study. The analysis of Fusarium mycotoxin levels in the two experimental diets were described in our previous study [31]. The NC diet contained $221.10 \mu \mathrm{g} / \mathrm{kg}$ DON, $12.12 \mu \mathrm{g} / \mathrm{kg}$ 3-acetyl DON, $32.95 \mu \mathrm{g} / \mathrm{kg}$ 15-acetyl DON, and $266.26 \mu \mathrm{g} / \mathrm{kg}$ total DON. The MC diet contained $825.46 \mu \mathrm{g} / \mathrm{kg}$ DON, $212.79 \mu \mathrm{g} / \mathrm{kg}$ 3-acetyl DON, $59.45 \mu \mathrm{g} / \mathrm{kg}$ 15-acetyl DON, $1097.99 \mu \mathrm{g} / \mathrm{kg}$ total DON, and $501.56 \mu \mathrm{g} / \mathrm{kg}$ ZEN, which were each significantly higher $(p<0.05)$ than in the NC diet. In the current study, the levels of DON in the contaminated diet were expected in natural conditions, which is similar with a previous Chinese report showing the mean DON levels were $753.1-1194.0 \mu \mathrm{g} / \mathrm{kg}$ and the maximum levels reached to $4279.3 \mu \mathrm{g} / \mathrm{kg}$ in complete pig feed between 2016 and 2017 [51].

\subsection{Animals}

In the swine industry, weaning piglets face enormous stress, which leads to perturbations in gut microbiota, host physiological, and mucosal immune function, such as microbiological, environmental, and dietary factors [28]. In addition, corn and soybean meal represent over $50 \%$ of the total dietary ingredients, which is often contaminated with mycotoxins [29], which will aggravate the post-weaning stress and induce higher economic losses. Therefore, piglets are a good model to explore the effects of Fusarium mycotoxins on microbiota. Furthermore, finding a way to minimize the side effects of mycotoxins on piglets should be valuable for swine production.

Therefore, a total of 24 clinically-healthy female weaning piglets (Landrace $\times$ large $\times$ white; initial average body weight, $7.25 \pm 1.02 \mathrm{~kg}$ ) from six litters (four pigs/little) were individually housed in pens $(1.2$ by $2.0 \mathrm{~m}$ ) with one feeder and one nipple drinker. The piglets had ab libitum access to feed and water. This protocol was approved by the Committee of Animal Research Institute (Certification No. SYXK(Su)2011-0036, 11 August 2015), Nanjing Agricultural University, China.

\subsection{Experimental Design and Sampling}

After a six day adaption period, the animals were randomly assigned to four treatment groups (NC, MC, MC + HRW and MC + LAC, respectively), with six piglets in each group. The piglets were fed their corresponding experimental diets for 25 days. The piglets in the NC group were fed an uncontaminated control diet, while piglets in the MC, MC + HRW, and MC + LAC groups were fed Fusarium mycotoxin-contaminated diets.

Piglets in each group received oral administration with their corresponding treatment twice a day (1000 and $1400 \mathrm{~h}$ ) through a $6 \times 200 \mathrm{~mm}$ nasogastric tube (Jiangsu Huatai Medical Devices Company, Yangzhou, China). The hydrogen-free water was orally administered at $10 \mathrm{~mL} / \mathrm{kg}$ body weight (BW) to piglets in both NC and MC groups. While piglets in the $\mathrm{MC}+\mathrm{HRW}$ group received $10 \mathrm{~mL} / \mathrm{kg}$ BW HRW (Beijing Hydrovita Biotechnology Company, Beijing, China). The HRW was produced by dissolving high-pressure hydrogen gas into pure water, and kept in $300 \mathrm{~mL}$ aluminum pouches at room temperature. At least $0.6 \mathrm{mM}$ levels of hydrogen were detected in the HRW, and they were administered to piglets within $15 \mathrm{~min}$ after opening. Lactulose (4-O- $\beta$-D-galactosyl-D-fructose; formula, $\mathrm{C}_{12} \mathrm{H}_{22} \mathrm{O}_{11}$; CAS number, 4618-18-2) was used in this study. A dose of $500 \mathrm{mg} / \mathrm{kg}$ BW of LAC oral solution (Abbott Healthcare Products, Weesp, The Netherlands) was dissolved in $10 \mathrm{~mL} / \mathrm{kg}$ BW of hydrogen-free water, and administrated to piglets in the MC + LAC group.

The amounts of LAC and HRW were dependent on the body weight and updated weekly. One piglet was removed from the MC, MC + LAC, and MC + HRW groups fed with a Fusarium mycotoxin diet due to poor health condition. Therefore, five independent replicates from each group were used in this study. On day 25, $30 \mathrm{~min}$ after administration of different treatments, piglets were euthanized by an intramuscular injection of sodium pentobarbital $(40 \mathrm{mg} / \mathrm{kg} \mathrm{BW})$. The whole cecum 
and colon were obtained and weighted. Digesta samples from jejunum, ileum, colon, and caecum were collected and stored at $-70^{\circ} \mathrm{C}$ for further analysis.

\subsection{Feces Scoring}

Piglets were closely observed daily for clinical signs of diarrhea and a scoring system was applied to indicate the presence and severity of diarrhea as previously described [52]. Feces scoring began on day 0 on the experimental diets and continued until day 25. Scores were given daily watch and the average fecal score value per piglets was given. The following feces scoring system was used: $1=$ hard feces, 2 = slightly soft feces, 3 = soft, partially formed feces, $4=$ loose, semiliquid feces, and $5=$ watery, mucous-like feces.

\subsection{Hydrogen Gas Measurement in Different Intestine Segments}

Hydrogen levels in the mucosa samples from different intestine segments were analyzed using a hydrogen sensor (Unisense, Aarhus, Denmark) as previously described [53]. Briefly, piglets were euthanized with sodium pentobarbital and placed in supine position. Incisions were made in the segments of stomach, duodenum, jejunum, ileum, colon and cecum. The digesta were removed and hydrogen microelectrode (diameter, $50 \mu \mathrm{m}$ ) was penetrated into the mucosa at a depth of $200 \mu \mathrm{m}$.

\subsection{SCFA Detection in the Digesta of Different Intestine Segements}

The digesta samples $(0.3 \mathrm{~g})$ was weighed and mixed with $0.9 \mathrm{~mL}$ of meta-phosphoric acid $(25 \%, w / v)$ and crotonic acid $(75 \mathrm{mM})$ solution. The mixture was vortexed and centrifuged at $12,000 \times \mathrm{g}$ for $10 \mathrm{~min}$ at $4{ }^{\circ} \mathrm{C}$, and the supernatant was stored at $-20^{\circ} \mathrm{C}$ until assay. After thawing, the supernatant was centrifuged at $12,000 \times g$ for $5 \mathrm{~min}$, and the supernatant was used for SCFA detection. The supernatant was detected by using a capillary column gas chromatograph (GC-14A with an FID detector; Shimadzu, Japan; capillary column: $30 \mathrm{~m} \times 0.32 \mathrm{~mm} \times 0.25 \mu \mathrm{m}$ film thickness) with a $\mathrm{H}_{2}$ flame ionization detector and split injection as previously described [54]. The column, injector, and detector temperature were $140^{\circ} \mathrm{C}, 180^{\circ} \mathrm{C}$, and $180^{\circ} \mathrm{C}$, respectively.

\subsection{DNA Isolation, PCR Amplification, and DGGE Analysis}

Total DNA of the jejunum, ileum, colon, and caecum digesta samples were extracted by a QIAamp ${ }^{\circledR}$ DNA Stool Mini Kit (Qiagen, Germany) according to the manufacturer's instructions. PCR products of the total bacteria and methanogenic Archaea for denaturing gradient gel electrophoresis (DGGE) analysis were amplified with specific primers (Table S3) and separated in denaturing gradient polyacrylamide gels as previously described [55].

\subsection{Real-Time PCR Assays for Quantification of the Selected Bacteria}

The abundance of total bacteria, Lactobacillus, Bifidobacterium, Escherichia coli, Enterococcus, methanogenic Archaea, sulfate-reducing bacteria, and acetogenic bacteria were quantified by real-time PCR using specific primers (Table S3). Standard curves of each bacterial group were generated using triplicate ten-fold dilutions of known copy numbers of a target gene cloned into a plasmid vector. Real-time PCR was carried out on SetpOnePlusTM Real-Time PCR System (Life Technologies, Carlsbad, CA, USA) by using SYBR Premix Ex Taq (Takara, Dalian, China).

\subsection{Statistical Analyses}

Data from DGGE gels were calculated as previously described [55]. All statistical analyses were performed by one-way ANOVA with SPSS statistical software (version 18.0 for Windows, SPSS Inc., Chicago, IL, USA, 2009). The differences among treatments were considered significant at $p<0.05$. Differences among treatments were determined using the Tukey-Kramer test. 
Supplementary Materials: The following are available online at http:/ / www.mdpi.com/2072-6651/10/6/246/s1, Table S1: Effects of hydrogen-rich water and lactulose on $\mathrm{pH}$ values in different intestine segments in piglets fed Fusarium mycotoxins contaminated diets, Table S2: Ingredient composition and nutrient contents of control and experimental diets, Table S3: Primers sequences used in this study, Figure S1: Effects of lactulose and hydrogen water on the relative colon and caecum weights of piglets fed Fusarium mycotoxins contaminated diet.

Author Contributions: W.Z. and W.Y. have contributed to the conception and the design of the study; X.J., and Q.Z., carried out the experiments; X.J. and Q.Z. analyzed the data; W.Z., and W.Y. contributed the reagents/materials/analysis tools; W.Z. drafted the manuscript; W.Z. and W.Y. revised the article. All authors read and approved final manuscript.

Funding: This work was funded by the National Nature Science Foundation of China (31501986), the Fundamental Research Funds for Central Universities (KJQN201611) and Jiangsu Modern Agricultural (Pig) Industrial Technology System (SXGC(2017)286).

Acknowledgments: The authors would like to thank Dr. Ming-Guo Zhou and Dr. Ya-bing Duan for providing the Fusarium graminearum strain 2021 and preparing the conidia. We thank Dr. Jin Cui for her kindly aid with hydrogen measurements in the samples from the piglets. We also would like thank Dr. Tao Shao and Dr. Xianjun Yan for their kindly aid with SCFAs detection.

Conflicts of Interest: The authors declare no conflict of interest.

\section{References}

1. Cortinovis, C.; Pizzo, F.; Spicer, L.J.; Caloni, F. Fusarium mycotoxins: Effects on reproductive function in domestic animals-A review. Theriogenology 2013, 80, 557-564. [CrossRef] [PubMed]

2. Doll, S.; Danicke, S. The fusarium toxins deoxynivalenol (don) and zearalenone (zon) in animal feeding. Prev. Vet. Med. 2011, 102, 132-145. [CrossRef] [PubMed]

3. Antonissen, G.; Martel, A.; Pasmans, F.; Ducatelle, R.; Verbrugghe, E.; Vandenbroucke, V.; Li, S.; Haesebrouck, F.; Van Immerseel, F.; Croubels, S. The impact of fusarium mycotoxins on human and animal host susceptibility to infectious diseases. Toxins 2014, 6, 430-452. [CrossRef] [PubMed]

4. Kollarczik, B.; Gareis, M.; Hanelt, M. In vitro transformation of the fusarium mycotoxins deoxynivalenol and zearalenone by the normal gut microflora of pigs. Nat. Toxins 1994, 2, 105-110. [CrossRef] [PubMed]

5. Karlovsky, P. Biological detoxification of the mycotoxin deoxynivalenol and its use in genetically engineered crops and feed additives. Appl. Microbiol. Biotechnol. 2011, 91, 491-504. [CrossRef] [PubMed]

6. Wache, Y.J.; Valat, C.; Postollec, G.; Bougeard, S.; Burel, C.; Oswald, I.P.; Fravalo, P. Impact of deoxynivalenol on the intestinal microflora of pigs. Int. J. Mol. Sci. 2009, 10, 1-17. [CrossRef] [PubMed]

7. Piotrowska, M.; Slizewska, K.; Nowak, A.; Zielonka, L.; Zakowska, Z.; Gajecka, M.; Gajecki, M. The effect of experimental fusarium mycotoxicosis on microbiota diversity in porcine ascending colon contents. Toxins 2014, 6, 2064-2081. [CrossRef] [PubMed]

8. Ge, L.; Yang, M.; Yang, N.N.; Yin, X.X.; Song, W.G. Molecular hydrogen: A preventive and therapeutic medical gas for various diseases. Oncotarget 2017, 8, 102653-102673. [CrossRef] [PubMed]

9. Ohsawa, I.; Ishikawa, M.; Takahashi, K.; Watanabe, M.; Nishimaki, K.; Yamagata, K.; Katsura, K.; Katayama, Y.; Asoh, S.; Ohta, S. Hydrogen acts as a therapeutic antioxidant by selectively reducing cytotoxic oxygen radicals. Nat. Med. 2007, 13, 688-694. [CrossRef] [PubMed]

10. Kajiya, M.; Silva, M.J.B.; Sato, K.; Ouhara, K.; Kawai, T. Hydrogen mediates suppression of colon inflammation induced by dextran sodium sulfate. BBRC 2009, 386, 11-15. [CrossRef] [PubMed]

11. Zheng, X.; Mao, Y.; Cai, J.; Li, Y.; Liu, W.; Sun, P.; Zhang, J.H.; Sun, X.; Yuan, H. Hydrogen-rich saline protects against intestinal ischemia/reperfusion injury in rats. Free Radic. Res. 2009, 43, 478-484. [CrossRef] [PubMed]

12. Wolf, P.G.; Biswas, A.; Morales, S.E.; Greening, C.; Gaskins, H.R. H2 metabolism is widespread and diverse among human colonic microbes. Gut Microbes 2016, 7, 235-245. [CrossRef] [PubMed]

13. Shimamura, Y.; Shinke, M.; Hiraishi, M.; Tsuchiya, Y.; Masuda, S. The application of alkaline and acidic electrolyzed water in the sterilization of chicken breasts and beef liver. Food Sci. Nutr. 2016, 4, 431-440. [CrossRef] [PubMed]

14. Xiao, H.W.; Li, Y.; Luo, D.; Dong, J.L.; Zhou, L.X.; Zhao, S.Y.; Zheng, Q.S.; Wang, H.C.; Cui, M.; Fan, S.J. Hydrogen-water ameliorates radiation-induced gastrointestinal toxicity via myd88's effects on the gut microbiota. Exp. Mol. Med. 2018, 50, e433. [CrossRef] [PubMed]

15. Panesar, P.S.; Kumari, S. Lactulose: Production, purification and potential applications. Biotechnol. Adv. 2011, 29, 940-948. [CrossRef] [PubMed] 
16. Yu, J.; Zhang, W.; Zhang, R.; Ruan, X.; Ren, P.; Lu, B. Lactulose accelerates liver regeneration in rats by inducing hydrogen. J. Surg. Res. 2015, 195, 128-135. [CrossRef] [PubMed]

17. Zhai, X.; Chen, X.; Shi, J.; Shi, D.; Ye, Z.; Liu, W.; Li, M.; Wang, Q.; Kang, Z.; Bi, H.; et al. Lactulose ameliorates cerebral ischemia-reperfusion injury in rats by inducing hydrogen by activating nrf2 expression. Free Radic. Biol. Med. 2013, 65, 731-741. [CrossRef] [PubMed]

18. Chae, J.P.; Pajarillo, E.A.B.; Park, C.-S.; Kang, D.-K. Lactulose increases bacterial diversity and modulates the swine faecal microbiome as revealed by 454-pyrosequencing. Anim. Feed Sci. Technol. 2015, 209, 157-166. [CrossRef]

19. Zheng, W.; Hou, Y.; Su, Y.; Yao, W. Lactulose promotes equol production and changes the microbial community during in vitro fermentation of daidzein by fecal inocula of sows. Anaerobe 2014, 25, 47-52. [CrossRef] [PubMed]

20. Sommer, F.; Backhed, F. The gut microbiota-Masters of host development and physiology. Nat. Rev. Microbiol. 2013, 11, 227-238. [CrossRef] [PubMed]

21. Slavin, J. Fiber and prebiotics: Mechanisms and health benefits. Nutrients 2013, 5, 1417-1435. [CrossRef] [PubMed]

22. Zhao, W.J.; Wang, Y.P.; Liu, S.Y.; Huang, J.J.; Zhai, Z.X.; He, C.; Ding, J.M.; Wang, J.; Wang, H.J.; Fan, W.B.; et al. The dynamic distribution of porcine microbiota across different ages and gastrointestinal tract segments. PLoS ONE 2015, 10. [CrossRef] [PubMed]

23. Liu, C.; Kurokawa, R.; Fujino, M.; Hirano, S.; Sato, B.; Li, X.K. Estimation of the hydrogen concentration in rat tissue using an airtight tube following the administration of hydrogen via various routes. Sci. Rep. 2014, 4. [CrossRef]

24. Watanabe, M.; Kamimura, N.; Iuchi, K.; Nishimaki, K.; Yokota, T.; Ogawa, R.; Ohta, S. Protective effect of hydrogen gas inhalation on muscular damage using a mouse hindlimb ischemia-reperfusion injury model. Plast. Reconstr. Surg. 2017, 140, 1195-1206. [CrossRef]

25. Hong, Y.; Chen, S.; Zhang, J. Hydrogen as a selective antioxidant: A review of clinical and experimental studies. J. Int. Med. Res. 2010, 38, 1893-1903. [CrossRef] [PubMed]

26. Chen, X.; Zuo, Q.; Hai, Y.; Sun, X.J. Lactulose: An indirect antioxidant ameliorating inflammatory bowel disease by increasing hydrogen production. Med. Hypotheses 2011, 76, 325-327. [CrossRef] [PubMed]

27. Chen, X.; Zhai, X.; Shi, J.; Liu, W.W.; Tao, H.; Sun, X.; Kang, Z. Lactulose mediates suppression of dextran sodium sulfate-induced colon inflammation by increasing hydrogen production. Dig. Dis. Sci. 2013, 58, 1560-1568. [CrossRef] [PubMed]

28. Campbell, J.M.; Crenshaw, J.D.; Polo, J. The biological stress of early weaned piglets. J. Anim. Sci. Biotechnol. 2013, 4. [CrossRef] [PubMed]

29. Daga, A.; Horn, M.B.; Kottwitz, L.B.M.; de Farina, L.O. Bromatological and mycotoxin analysis on soybean meal before and after the industrial process of micronization. Cienc. Rural 2015, 45, 1336-1341. [CrossRef]

30. Heo, J.M.; Opapeju, F.O.; Pluske, J.R.; Kim, J.C.; Hampson, D.J.; Nyachoti, C.M. Gastrointestinal health and function in weaned pigs: A review of feeding strategies to control post-weaning diarrhoea without using in-feed antimicrobial compounds. J. Anim. Physiol. Anim. Nutr. 2013, 97, 207-237. [CrossRef] [PubMed]

31. Zheng, W.; Ji, X.; Zhang, Q.; Du, W.; Wei, Q.; Yao, W. Hydrogen-rich water and lactulose protect against growth suppression and oxidative stress in female piglets fed fusarium toxins contaminated diets. Toxins 2018, 10, 228. [CrossRef] [PubMed]

32. Gahan, D.A.; Lynch, M.B.; Callan, J.J.; O'Sullivan, J.T.; O’Doherty, J.V. Performance of weanling piglets offered low-, medium- or high-lactose diets supplemented with a seaweed extract from laminaria spp. Animal 2009, 3, 24-31. [CrossRef] [PubMed]

33. Maresca, M. From the gut to the brain: Journey and pathophysiological effects of the food-associated trichothecene mycotoxin deoxynivalenol. Toxins 2013, 5, 784-820. [CrossRef] [PubMed]

34. Grenier, B.; Applegate, T.J. Modulation of intestinal functions following mycotoxin ingestion: Meta-analysis of published experiments in animals. Toxins 2013, 5, 396-430. [CrossRef] [PubMed]

35. Roberfroid, M.; Gibson, G.R.; Hoyles, L.; McCartney, A.L.; Rastall, R.; Rowland, I.; Wolvers, D.; Watzl, B.; Szajewska, H.; Stahl, B.; et al. Prebiotic effects: Metabolic and health benefits. Br. J. Nutr. 2010, 104 (Suppl. 2), S1-S63. [CrossRef] [PubMed]

36. Krueger, M.; Schroedl, W.; Isik, W.; Lange, W.; Hagemann, L. Effects of lactulose on the intestinal microflora of periparturient sows and their piglets. Eur. J. Nutr. 2002, 41 (Suppl. 1), I26-I31. [CrossRef] [PubMed] 
37. Guerra-Ordaz, A.A.; Molist, F.; Hermes, R.G.; de Segura, A.G.; La Ragione, R.M.; Woodward, M.J.; Tchorzewska, M.A.; Collins, J.W.; Pérez, J.F.; Martín-Orúe, S.M. Effect of inclusion of lactulose and lactobacillus plantarum on the intestinal environment and performance of piglets at weaning. Anim. Feed Sci. Technol. 2013, 185, 160-168. [CrossRef]

38. Richards, J.D.; Gong, J.; de Lange, C.F.M. The gastrointestinal microbiota and its role in monogastric nutrition and health with an emphasis on pigs: Current understanding, possible modulations, and new technologies for ecological studies. Can. J. Anim. Sci. 2005, 85, 421-435. [CrossRef]

39. Kamphues, J.; Tabeling, R.; Stuke, O.; Bollmann, S.; Amtsberg, G. Investigations on potential dietetic effects of lactulose in pigs. Livest. Sci. 2007, 109, 93-95. [CrossRef]

40. Calik, A.; Ergun, A. Effect of lactulose supplementation on growth performance, intestinal histomorphology, cecal microbial population, and short-chain fatty acid composition of broiler chickens. Poult. Sci. 2015, 94, 2173-2182. [CrossRef] [PubMed]

41. Martín-Peláez, S.; Costabile, A.; Hoyles, L.; Rastall, R.A.; Gibson, G.R.; La Ragione, R.M.; Woodward, M.J.; Mateu, E.; Martín-Orúe, S.M. Evaluation of the inclusion of a mixture of organic acids or lactulose into the feed of pigs experimentally challenged with salmonella typhimurium. Vet. Microbiol. 2010, 142, 337-345. [CrossRef] [PubMed]

42. Danicke, S.; Matthaus, K.; Lebzien, P.; Valenta, H.; Stemme, K.; Ueberschar, K.H.; Razzazi-Fazeli, E.; Bohm, J.; Flachowsky, G. Effects of fusarium toxin-contaminated wheat grain on nutrient turnover, microbial protein synthesis and metabolism of deoxynivalenol and zearalenone in the rumen of dairy cows. J. Anim. Physiol. Anim. Nutr. 2005, 89, 303-315. [CrossRef] [PubMed]

43. Ali-Vehmas, T.; Rizzo, A.; Westermarck, T.; Atroshi, F. Measurement of antibacterial activities of t-2 toxin, deoxynivalenol, ochratoxin a, aflatoxin b1 and fumonisin b1 using microtitration tray-based turbidimetric techniques. Zentralbl. Veterinarmed. A 1998, 45, 453-458. [CrossRef] [PubMed]

44. Burel, C.; Tanguy, M.; Guerre, P.; Boilletot, E.; Cariolet, R.; Queguiner, M.; Postollec, G.; Pinton, P.; Salvat, G.; Oswald, I.P.; et al. Effect of low dose of fumonisins on pig health: Immune status, intestinal microbiota and sensitivity to salmonella. Toxins 2013, 5, 841-864. [CrossRef] [PubMed]

45. Maresca, M.; Fantini, J. Some food-associated mycotoxins as potential risk factors in humans predisposed to chronic intestinal inflammatory diseases. Toxicon 2010, 56, 282-294. [CrossRef] [PubMed]

46. Guerra-Ordaz, A.A.; Gonzalez-Ortiz, G.; La Ragione, R.M.; Woodward, M.J.; Collins, J.W.; Perez, J.F.; Martin-Orue, S.M. Lactulose and lactobacillus plantarum, a potential complementary synbiotic to control postweaning colibacillosis in piglets. Appl. Environ. Microbiol. 2014, 80, 4879-4886. [CrossRef] [PubMed]

47. Naito, Y.; Higashimura, Y.; Baba, Y.; Inoue, R.; Takagi, T.; Uchiyama, K.; Mizushima, K.; Hirai, Y.; Ushiroda, C.; Tanaka, Y. Effects of molecular hydrogen-dissolved alkaline electrolyzed water on intestinal environment in mice. Med. Gas Res. 2018, 8, 6. [CrossRef] [PubMed]

48. Liu, S.; Duan, Y.; Ge, C.; Chen, C.; Zhou, M. Functional analysis of the beta2-tubulin gene of fusarium graminearum and the beta-tubulin gene of botrytis cinerea by homologous replacement. Pest Manag. Sci. 2013, 69, 582-588. [CrossRef] [PubMed]

49. National Research Council (U.S.). Committee on Nutrient Requirements of Swine. In Nutrient Requirements of Swine, 11th ed.; National Academies Press: Washington, DC, USA, 2012.

50. Xiao, H.; Wu, M.M.; Tan, B.E.; Yin, Y.L.; Li, T.J.; Xiao, D.F.; Li, L. Effects of composite antimicrobial peptides in weanling piglets challenged with deoxynivalenol: I. Growth performance, immune function, and antioxidation capacity. J. Anim. Sci. 2013, 91, 4772-4780. [CrossRef] [PubMed]

51. Ma, R.; Zhang, L.; Liu, M.; Su, Y.T.; Xie, W.M.; Zhang, N.Y.; Dai, J.F.; Wang, Y.; Rajput, S.A.; Qi, D.S.; et al. Individual and combined occurrence of mycotoxins in feed ingredients and complete feeds in China. Toxins 2018, 10, 113. [CrossRef] [PubMed]

52. Walsh, A.M.; Sweeney, T.; O'Shea, C.J.; Doyle, D.N.; O’Doherty, J.V. Effect of supplementing different ratios of laminarin and fucoidan in the diet of the weanling piglet on performance, nutrient digestibility, and fecal scoring. J. Anim. Sci. 2012, 90, 215-217. [CrossRef] [PubMed]

53. Sun, H.; Chen, L.; Zhou, W.; Hu, L.; Li, L.; Tu, Q.; Chang, Y.; Liu, Q.; Sun, X.; Wu, M.; et al. The protective role of hydrogen-rich saline in experimental liver injury in mice. J. Hepatol. 2011, 54, 471-480. [CrossRef] [PubMed] 
54. Mao, S.Y.; Zhu, W.Y.; Wang, Q.J.; Yao, W. Effect of daidzein on in vitro fermentation by microorganisms from the goat rumen Anim. Feed Sci. Technol. 2007, 136, 154-163. [CrossRef]

55. Zheng, W.; Hou, Y.; Yao, W. Lactulose increases equol production and improves liver antioxidant status in barrows treated with daidzein. PLoS ONE 2014, 9, e93163. [CrossRef] [PubMed] 